\title{
Stereotactic radiosurgery for arteriovenous malformations of the postgeniculate visual pathway
}

\author{
Greg Bowden, MD, MSc, ${ }^{1,3,5}$ Hideyuki Kano, MD, PhD, ${ }^{1,3}$ Ellen Caparosa, BS, ${ }^{4}$ Daniel Tonetti, MD, ${ }^{4}$ \\ Ajay Niranjan MCH, MBA, ${ }^{1,3}$ Edward A. Monaco III, MD, PhD, ${ }^{1,3}$ John Flickinger, MD, ${ }^{2,3}$ \\ Yoshio Arai, MD, ${ }^{2,3}$ and L. Dade Lunsford, MD ${ }^{1,3}$
}

Departments of ${ }^{1}$ Neurological Surgery and ${ }^{2}$ Radiation Oncology; ${ }^{3}$ Center for Image-Guided Neurosurgery; ${ }^{4}$ University of Pittsburgh School of Medicine, University of Pittsburgh, Pennsylvania; and ${ }^{5}$ University of Western Ontario, London, Ontario, Canada

OBJECT A visual field deficit resulting from the management of an arteriovenous malformation (AVM) significantly impacts a patient's quality of life. The present study was designed to investigate the clinical and radiological outcomes of stereotactic radiosurgery (SRS) performed for AVMs involving the postgeniculate visual pathway.

METHODS In this retrospective single-institution analysis, the authors reviewed their experience with Gamma Knife surgery for postgeniculate visual pathway AVMs performed during the period between 1987 and 2009.

RESULTS During the study interval, 171 patients underwent SRS for AVMs in this region. Forty-one patients (24\%) had a visual deficit prior to SRS. The median target volume was $6.0 \mathrm{~cm}^{3}$ (range $0.4-22 \mathrm{~cm}^{3}$ ), and 19 Gy (range 14-25 Gy) was the median margin dose. Obliteration of the AVM was confirmed in 80 patients after a single SRS procedure at a median follow-up of 74 months (range 5-297 months). The actuarial rate of total obliteration was $67 \%$ at 4 years. Arteriovenous malformations with a volume $<5 \mathrm{~cm}^{3}$ had obliteration rates of $60 \%$ at 3 years and $79 \%$ at 4 years. The delivered margin dose proved significant given that $82 \%$ of patients receiving $\geq 22 \mathrm{~Gy}$ had complete obliteration. The AVM was completely obliterated in an additional 18 patients after they underwent repeat SRS. At a median of 25 months (range 11-107 months) after SRS, 9 patients developed new or worsened visual field deficits. One patient developed a complete homonymous hemianopia, and 8 patients developed quadrantanopias. The actuarial risk of sustaining a new visual deficit was $3 \%$ at 3 years, $5 \%$ at 5 years, and $8 \%$ at 10 years. Fifteen patients had hemorrhage during the latency period, resulting in death in 9 of the patients. The annual hemorrhage rate during the latency interval was $2 \%$, and no hemorrhages occurred after confirmed obliteration.

CONCLUSIONS Despite an overall treatment mortality of $5 \%$, related to latency interval hemorrhage, SRS was associated with only a $5.6 \%$ risk of new visual deficit and a final obliteration rate close to $80 \%$ in patients with AVMs of the postgeniculate visual pathway.

http://thejns.org/doi/abs/10.3171/2014.10.JNS1453

KEY WORDS arteriovenous malformation; AVM; optic radiation; stereotactic radiosurgery; Gamma Knife; vision; vascular disorders

$\mathrm{M}$ ANAGEMENT options for arteriovenous malformations (AVMs) have expanded and evolved over time. However, the underlying goal of intervention remains complete obliteration of the AVM and maintenance of neurological function. ${ }^{16,40,41}$ The rates of AVM occlusion after a single Gamma Knife surgery generally range from $70 \%$ to $80 \%$ over a 5-year observation period..$^{6,11,19,25}$ In addition, stereotactic radiosurgery (SRS) has a relatively low risk profile for adverse radiation effects (AREs). ${ }^{23}$

The lateral geniculate nucleus gives rise to the sublenticular and retrolenticular segments of the optic radiation that travel through the temporal and parietal lobes, respectively, on a path that terminates in the striate cortex. Because the distance and fragility of these pathways create the opportunity for disruption by an AVM, associ-

ABBREVIATIONS ARE = adverse radiation effect; $A V M=$ arteriovenous malformation; SRS = stereotactic radiosurgery.

SUBMITTED January 8, 2014. ACCEPTED October 14, 2014.

INCLUDE WHEN CITING Published online November 28, 2014; DOI: 10.3171/2014.10.JNS1453.

DISCLOSURE The authors report no conflict of interest concerning the materials or methods used in this study or the findings specified in this paper. Dr. Lunsford is a

consultant and stockholder for AB Elekta. 
ated hemorrhage, or procedural intervention, visual field deficits are a common risk. Visual field deficits are most apparent in the occipital lobe where homonymous field defects have been reported, occurring in up to $81 \%$ of patients with AVM hemorrhages and in $36 \%$ of patients without a hemorrhage. ${ }^{13}$

New visual field deficits have been reported in all treatment paradigms and can occur in as many as 33\% of microsurgical patients. ${ }^{1,3}$ Unfortunately, such deficits can be a significant disability that negatively impacts quality of life and can worsen long-term rehabilitation outcomes, especially when a homonymous hemianopia has occurred..$^{5,8,32}$ A sparse collection of reports highlighting multimodality AVM treatment paradigms and visual field deficits has been published. However, an updated study focused on SRS treatment has been absent. In this study, we sought to evaluate the outcomes of Gamma Knife radiosurgery on postgeniculate visual pathway AVMs with a focus on visual field deficits.

\section{Methods \\ Study Design}

We conducted a single-institution retrospective analysis approved by the University of Pittsburgh Institutional Review Board. We evaluated outcomes for AVMs residing within the postgeniculate visual pathway and treated with Gamma Knife radiosurgery between 1987 and 2009. The AVMs occurred along the anatomically normal course of the optic radiation, which extends from the lateral geniculate body to the calcarine fissure. This course was further demarcated by Párraga et al., who indicated an anterior limit of the optic radiation at $5 \mathrm{~mm}$ posterior to the tip of the temporal horn and a lateral edge of approximately 20 $\mathrm{mm}$ from the cortical surface. ${ }^{28}$ The AVMs suitable for analysis were identified from our SRS database and were verified on imaging studies during the medical record review process independently conducted by two authors. Outcome data were collected through an independent medical record review and were analyzed by neurosurgeons who had not participated in the initial patient management.

\section{Radiosurgery Technique}

Expanded technical elements of the radiosurgery technique have been detailed in our previous publications. ${ }^{19,20}$ In brief, patients present on the day of treatment and intravenous conscious sedation is induced. The Leksell stereotactic frame is applied after a local anesthetic is administered to the pin sites. Axial high-resolution MRI is performed, followed by biplanar stereotactic angiography. The AVM nidus is outlined using a highly conformal radiosurgery dose plan that is created with Leksell GammaPlan software version 10 (Fig. 1). The selected margin dose was based on the volume and location of the AVM. In this study, we used Leksell Gamma Knife Models U, B, $\mathrm{C}, 4 \mathrm{C}$, and Perfexion units (Elekta AB).

\section{Patient Follow-Up}

Clinical and imaging follow-up (MRI when possible) is requested at 6,12,24, and 36 months after SRS. All pa- tients have serial clinical assessments of their visual fields using confrontation examinations. If a patient complains of a new visual field reduction or demonstrates such on confrontational examination, then a formal visual field test is requested. Furthermore, if any changes in neurological symptomatology, including visual disturbances, occur after SRS, the patient is promptly examined with imaging studies to assess for potential AREs. After 3 years, if MRI demonstrates total obliteration (no flow voids identified on T2-weighted MRI), then an angiography study is requested. Complete AVM obliteration on angiography is defined as the elimination of the AVM nidus and the absence of early draining veins. ${ }^{11}$ However, if a residual nidus is evident on imaging, then repeat SRS is recommended to achieve complete obliteration. Patients who undergo a second SRS procedure are again followed up with a similar protocol.

\section{Statistical Analysis}

Kaplan-Meier survival analysis was used to evaluate potential factors that affect results. Obliteration was calculated based on the time that MRI or angiography demonstrated complete occlusion of the AVM. The accuracy of MRI confirmation of obliteration is $96 \%$, as demonstrated by Pollock et al. ${ }^{30}$ We have shown that both MRI and angiography provide satisfactory evidence of AVM obliteration. ${ }^{11,37}$ Cox regression was used in a univariate analysis to calculate significant interactions between obliteration rates and related factors. A p value $<0.05$ was defined as statistically significant.

Hemorrhage results were calculated based on the time of a postradiosurgical bleeding event or loss to follow-up. The hemorrhage statistics were obtained through KaplanMeier survival analysis. The annual hemorrhage rate during the latency period was calculated based on the years of at-risk follow-up and the number of hemorrhages that occurred. Comparisons between various groups were performed as appropriate, using the Fisher exact and MannWhitney tests.

\section{Results \\ Patient Population and AVM Characteristics}

One hundred seventy-one patients underwent an initial single-stage SRS. At the time of SRS, the median patient age was 37 years (range 4-73 years). Eighty-nine patients were female and 82 were male. Arteriovenous malformations were functionally located within the postgeniculate optic radiation and anatomically located predominantly within the occipital lobe in 73 patients (43\%), the temporal lobe in 67 patients (39\%), and the parietal lobe in 31 patients (18\%) (Table 1) The initial presentation of these patients included intracranial hemorrhage in 61 patients (36\%), headaches in $54(32 \%)$, seizures in $45(26 \%)$, an incidental finding in 7 (4\%), and a visual field deficit in 4 (2\%). Neurological deficits were present before SRS in 50 patients (29\%). The primary causes of these neurological deficits were hemorrhage in 24 patients, adverse outcomes from embolization in 9 patients, and unknown in 17 patients. A visual defect was the primary neurological deficit in 41 patients, followed by hemiparesis (11 patients) and 


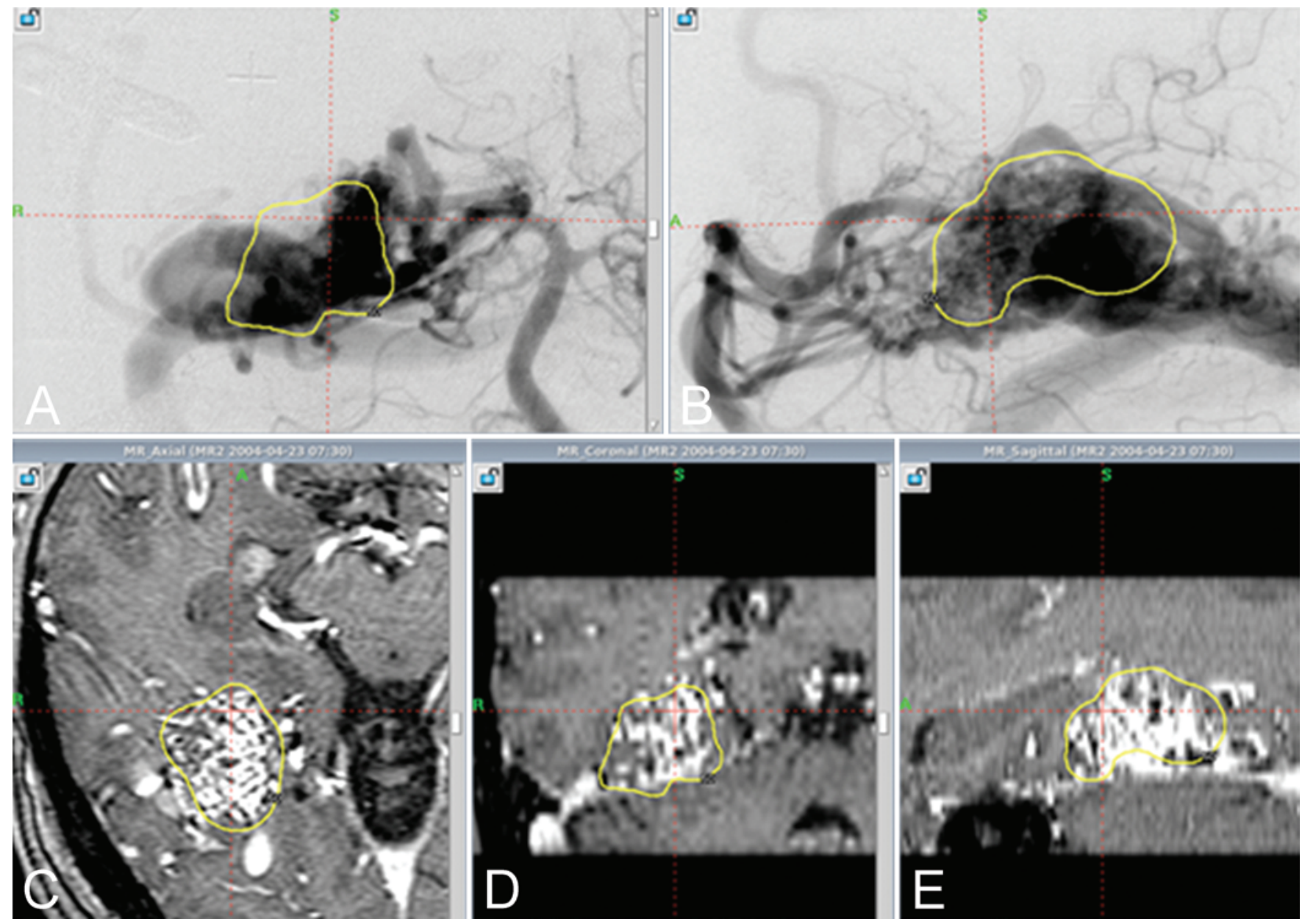

FIG. 1. Stereotactic radiosurgery planning using GammaPlan version 10 for optic radiation AVM. The AVM nidus was treated with $19 \mathrm{~Gy}$ at the $50 \%$ isodose line. Anteroposterior angiogram (A), lateral angiogram (B), sagittal T1-weighted MR image (C), coronal T1-weighted MR image (D), and axial T1-weighted MR image (E). Figure is available in color online only.

speech difficulties (2 patients). Five patients had multiple deficits.

Formal visual field testing (Goldmann field examination) was conducted if a field deficit was clinically observed during a confrontation visual field exam, was reported by a patient, or was highly suspected given the AVM's anatomical location. Thus, formal examinations were conducted in 97 patients. A homonymous hemianopia was seen in 11 patients, an upper quadrantanopia in 16, and a lower quadrantanopia in 14 . The visual defect was caused by prior hemorrhage in 24 patients, related to prior embolization in 4 patients, detected after prior surgical intervention in 1 patient, and related to the anatomical AVM location in the remaining patients.

Additional AVM characteristics included a coexisting aneurysm in 15 patients (9\%) and a venous outflow varix in 24 patients (14\%). Endovascular embolization had been performed in 37 patients (22\%) prior to the referral for SRS. Fifteen patients (9\%) had undergone craniotomy before SRS; 6 patients had undergone hematoma evacuation, 5 a partial AVM resection, 3 an aneurysm clipping, and 1 a ventriculostomy. Two experienced neurosurgeons had determined the Spetzler-Martin grade before SRS. ${ }^{35}$ A Grade I AVM was diagnosed in 8 patients (5\%), Grade
II AVM in 36 (21\%), Grade III in 86 (50\%), and Grade IV in $41(24 \%)$.

The median target volume was $6 \mathrm{~cm}^{3}\left(0.4-22 \mathrm{~cm}^{3}\right)$. The median margin dose was 19 Gy (14-25 Gy), and the maximum median dose was 36 Gy (25-50 Gy). The median number of isocenters used was 4 (range 1-17). At the conclusion of treatment, all patients received $20-40 \mathrm{mg}$ of intravenous methylprednisolone. Patient discharge from the hospital occurred within 2-24 hours postprocedure.

\section{Arteriovenous Malformation Response}

The median imaging follow-up after SRS was 74 months (5-297 months). Obliteration of the AVM was confirmed after initial SRS by using MRI or angiography in 80 patients. Actuarial rates of confirmed obliteration were $38 \%$ at 3 years and $67 \%$ at 4 years (Fig. 2). The median time until obliteration was 31 months (6-70 months). Fifty-eight patients had obliteration confirmed by angiography. As documented in previous studies, angiography results alone are falsely lowered because of patients who decline repeat angiography after obliteration is determined on MRI..$^{11,15,17}$

Several variables were significantly associated with AVM obliteration, according to univariate analysis. The 
TABLE 1. Summary of demographic and lesion characteristics in 171 patients with AVMs of the postgeniculate visual pathway

\begin{tabular}{lc}
\hline \multicolumn{1}{c}{ Characteristic } & No. of Cases (\%) \\
\hline Patients & 171 \\
\hline Median patient age in yrs & 37 \\
\hline Range of patient ages in yrs & $4-73$ \\
\hline Sex (M/F) & $82(48) / 89(52)$ \\
\hline AVM location & $73(43)$ \\
\hline Occipital lobe & $67(39)$ \\
\hline Temporal lobe & $31(18)$ \\
\hline Parietal lobe & $41(24)$ \\
\hline Prior visual field deficit & 11 \\
\hline Type of visual field deficit & 16 \\
\hline Homonymous hemianopia & 14 \\
\hline Upper quadrantanopia & $37(22)$ \\
\hline Lower quadrantanopia & $15(9)$ \\
\hline Prior embolization & $24(14)$ \\
\hline Prior surgery & $15(9)$ \\
\hline Varix present & $8(5)$ \\
\hline Coexisting aneurysm & $36(21)$ \\
\hline Spetzler-Martin grade & $86(50)$ \\
\hline I & $41(24)$ \\
\hline II &
\end{tabular}

median AVM target volumes were large in this series, which predictably affected obliteration rates. Arteriovenous malformations with a volume $<5 \mathrm{~cm}^{3}$ had an obliteration rate of $60 \%$ at 3 years and $79 \%$ at 4 years (Fig. $3)$. These smaller AVMs had a statistically higher obliteration rate with MRI confirmation ( $p<0.001)$. As the maximum AVM diameter increased, the rate of obliteration decreased $(p<0.001)$. Eighty-two percent of patients

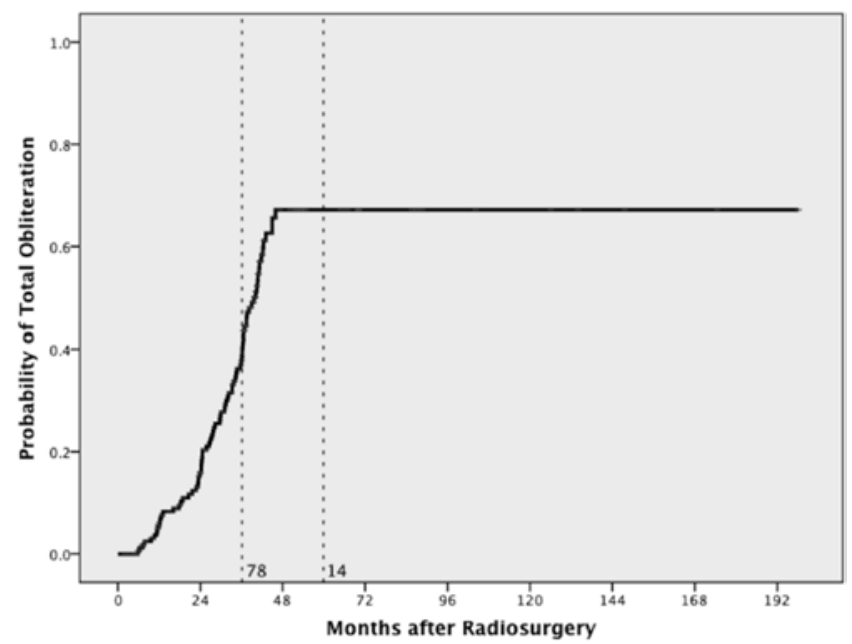

FIG. 2. Kaplan-Meier curve for total obliteration based on MRI and angiography studies combined. Vertical lines indicate 3 and 5 years, respectively. The number of patients remaining in the analysis is indicated at 3 (78 patients) and 5 (14 patients) years.

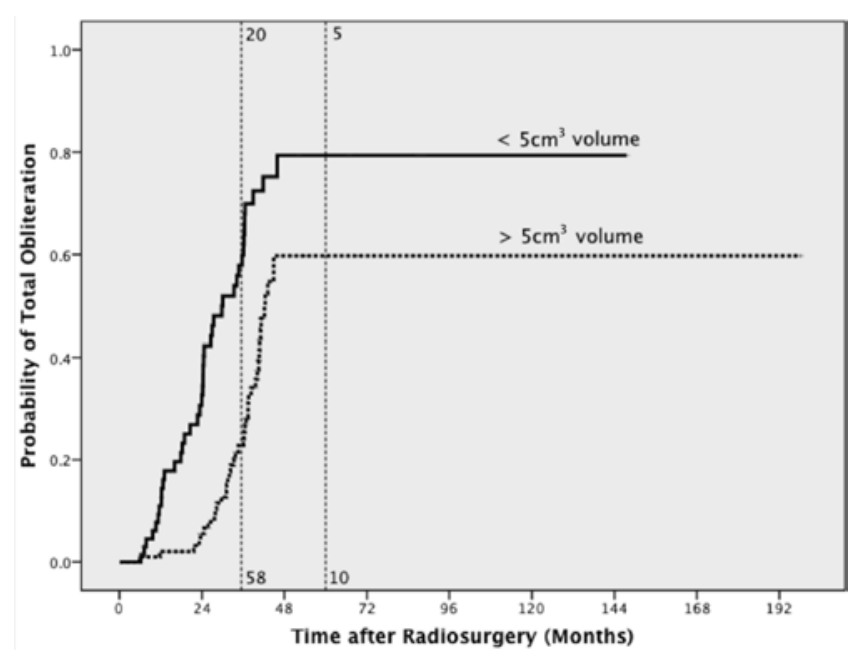

FIG. 3. Magnetic resonance imaging demonstrated total obliteration rates for AVMs with a volume less than (71 patients) or more than (100 patients) $5 \mathrm{~cm}^{3}$. Vertical lines appear at 3 and 5 years, respectively, with the associated number of patients remaining in the analysis indicated above for those with AVM volumes smaller than $5 \mathrm{~cm}^{3}$ and indicated below for those with AVM volumes larger than $5 \mathrm{~cm}^{3}$.

receiving a margin dose $\geq 22$ Gy had total AVM obliteration ( $<<0.001$; Fig. 4). Patients who had a prior AVM hemorrhage had improved obliteration rates $(p=0.035)$. In contrast, patients who had a prior embolization had lower obliteration rates $(\mathrm{p}=0.029)$.

\section{Visual Field Deficits}

Forty-one patients had a detected visual deficit prior to SRS. Thirty-six percent of patients with a hemorrhage at presentation had a visual deficit, compared with $19 \%$ of patients without a hemorrhage at presentation. Patients with a previous intracranial hemorrhage had a higher incidence of visual field deficits $(p=0.018)$. Patients who had undergone prior embolization had more visual deficits

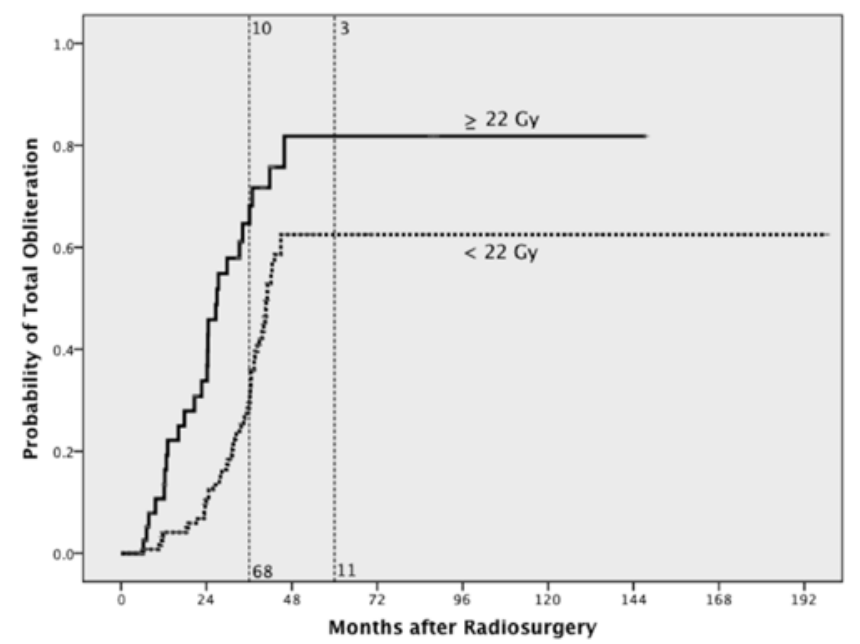

FIG. 4. Magnetic resonance imaging-demonstrated total obliteration rates comparing a margin dose $\geq 22$ Gy (40 patients) and < 22 Gy (131 patients). Vertical lines appear at 3 and 5 years, respectively, with the number of patients remaining in the analysis indicated above for those receiving $\geq 22$ Gy and indicated below for those receiving < 22 Gy. 
$(\mathrm{p}=0.004)$. Patients with prior seizure activity had fewer visual deficits $(\mathrm{p}=0.008)$. Nine patients $(22 \%)$ with a prior visual field deficit demonstrated an improvement in their symptoms at a median follow-up of 88 months.

Nine patients $(5.6 \%$, excluding patients who presented with homonymous hemianopia) had a change in their visual field after a single SRS procedure. Eight of these patients developed a new visual deficit, and 1 patient had worsening of an existing deficit without evidence of hemorrhage. The median time interval until detection of a new visual deficit was 25 months (11-107 months). The resulting deficits included superior quadrantanopia in 5 patients, inferior quadrantanopia in 3 patients, and complete homonymous hemianopia in 1 patient (Table 2). The actuarial rates of visual deficit were $3 \%$ at 3 years, $5 \%$ at 5 years, and $8 \%$ at 10 years (Fig. 5). Seven of these patients had undergone SRS alone, whereas 1 patient each had undergone embolization and surgery prior to SRS. Female patients had a higher incidence of visual field deficit $(p=0.036)$. Patients who required a second SRS procedure were more likely to develop a new visual deficit $(p=0.008)$. Adverse radiation effects were identified in 3 patients with visual field deficits. The presence of edema on follow-up MRI was associated with a higher rate of visual deficit $(\mathrm{p}=0.026)$. Two patients $(22 \%)$ with new-onset deficits postradiosurgery demonstrated improvement in their visual field deficit at the final follow-up (90 and 123 months, respectively).

All AVMs within the postgeniculate optic radiation were included in this analysis. There were 97 patients who had formal visual field testing, which included all patients who presented with a field deficit prior to the SRS procedure and all patients who developed a new visual field deficit. In this subgroup $10.5 \%$ of patients had a new or worsened deficit according to calculations that excluded preexisting homonymous hemianopia.

\section{Latency Interval Hemorrhage and Complication Risks}

Fifteen patients $(9 \%)$ had a single hemorrhage during the latency period at a median of 12 months (2-53 months). Eight patients died as a result of hemorrhage after SRS. Two patients died of unrelated cancer, and 5 patients died of undetermined causes. The cumulative rate of AVM hemorrhage after SRS was 5\% at 1 year, $9 \%$ at 3 years, and $10 \%$ at 5 years. The total number of hemorrhages was correlated with 387 patient-years of estimated hemorrhage risk, for an overall annual rate of $2.0 \%$ during the latency interval (the time from SRS treatment until obliteration or the last follow-up of a patient with a known residual AVM). No patient sustained a hemorrhage after MRI or angiography had confirmed AVM obliteration.

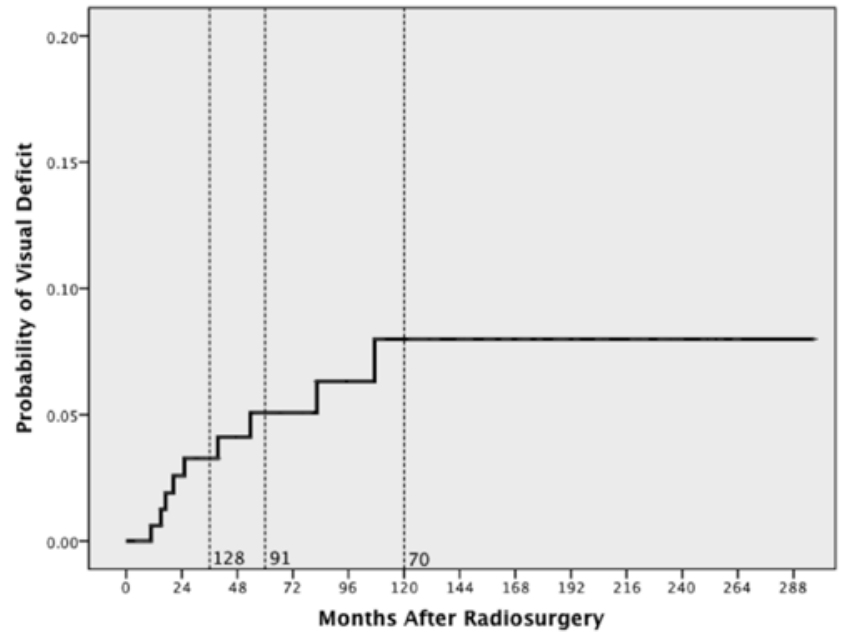

FIG. 5. A Kaplan-Meier survival curve depicting a new or worsened visual field deficit. The number of patients remaining in the analysis at 3,5 , and 10 -years, with each of these years marked by a vertical line, is indicated on the graph.

Seven patients (4\%) developed symptomatic AREs, defined as new T2 signal change surrounding the AVM target and associated with the development of new neurological signs in the absence of hemorrhage. Three patients had new or worsening seizure activity. Seizure activity returned to baseline in 2 of these patients after the administration of a short course of oral corticosteroids. As mentioned previously, 3 patients had a new or worsening visual field deficit. One patient exhibited new mild hemiparesis. Delayed cyst formation in the target region was detected in 4 individuals. The median time until cyst detection was 28 months (11-67 months). The cysts were asymptomatic in 3 patients, while 1 patient required surgical cyst fenestration.

\section{Repeat SRS}

Thirty patients with residual AVMs underwent a second SRS procedure at a median of 40 months (30-126 months) after the initial procedure. Twelve of these patients had confirmed obliteration on angiography, and 18 patients had confirmed obliteration on MRI or angiography at a median interval of 40 months (30-86 months) after the second SRS procedure (Fig. 6). One patient developed a new visual deficit (right homonymous hemianopia), which was identified 94 months after repeat SRS. A second patient developed a visual field deficit 165 months after a second SRS procedure, as the result of a hemorrhage.

TABLE 2. Visual field deficits before and after the SRS procedure

\begin{tabular}{|c|c|c|c|c|c|c|c|c|}
\hline \multirow[b]{2}{*}{ Category } & \multicolumn{4}{|c|}{ No. of Deficits } & \multicolumn{4}{|c|}{ Cause of Visual Deficit } \\
\hline & $\begin{array}{l}\text { Total Visual } \\
\text { Deficits }\end{array}$ & $\begin{array}{c}\text { Homonymous } \\
\text { Hemianopia }\end{array}$ & $\begin{array}{c}\text { Upper } \\
\text { Quadrantanopia }\end{array}$ & $\begin{array}{c}\text { Lower } \\
\text { Quadrantanopia }\end{array}$ & Hemorrhage & Embolization & SRS Effect & $\begin{array}{l}\text { Surgeryl } \\
\text { Unknown }\end{array}$ \\
\hline Prior to SRS & 41 & 11 & 16 & 14 & 23 & 4 & NA & 14 \\
\hline Single SRS & 9 & 1 & 5 & 3 & 0 & 0 & 9 & 0 \\
\hline Repeat SRS & 2 & 1 & 1 & 0 & 1 & 0 & 1 & 0 \\
\hline
\end{tabular}

$\mathrm{NA}=$ not applicable. 


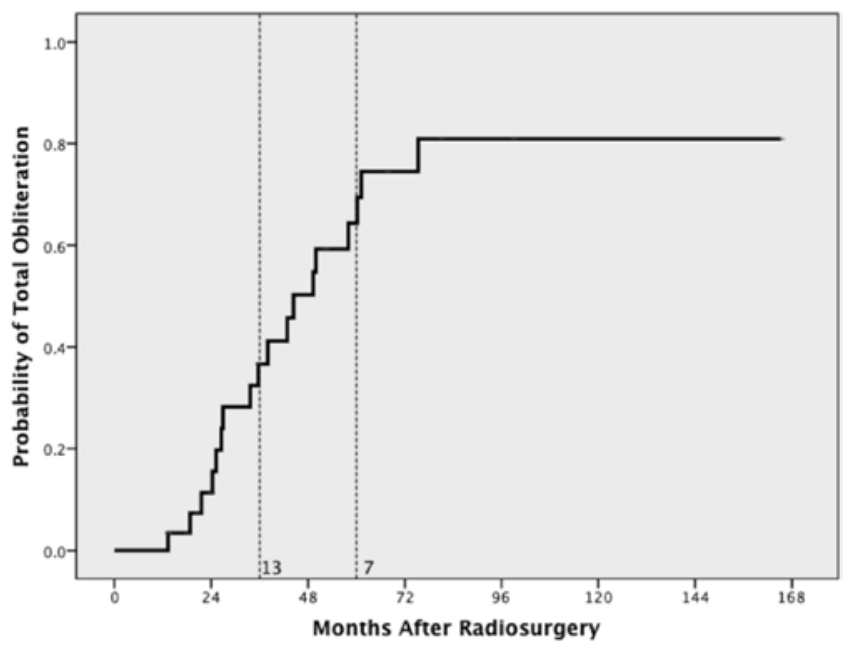

FIG. 6. Kaplan-Meier graph of total obliteration after repeat SRS based on MRI and angiography studies combined. The number of patients remaining in the analysis is indicated at 3 and 5 years (vertical lines).

\section{Discussion}

\section{Factors Related to Obliteration}

In this study we confirmed obliteration based on MRI or angiography in $67 \%$ of our patients at 4 years. Most patients in this series had larger average AVM volumes, which increases the risk of complications and reduces obliteration rates. In patients with an AVM $<5 \mathrm{~cm}^{3}$, the obliteration rate was $79 \%$ at 4 years. This result statistically demonstrated that higher obliteration rates occurred in smaller AVMs, which corresponds to the volume effect noted in previous studies. ${ }^{10,12,25,43}$ Total obliteration occurred more frequently when a higher margin dose was applied. In this study $82 \%$ of patients receiving $\geq 22$ Gy had occlusion of their AVM. While higher doses are more often prescribed for patients with smaller AVMs, the optimal dose still represents an empirical balance between the goal of obliteration and the associated risk of AREs. ${ }^{6,33,40}$ Patients with a prior AVM hemorrhage had a greater likelihood of AVM obliteration after SRS. Finally, patients previously treated with embolization had a decreased rate of total obliteration. This finding has been documented in the literature and may largely reflect a combination of technical difficulty due to embolization material obscuring the AVM and late revascularization of previously untreated regions. ${ }^{9}$

\section{Decision Making and Visual Fields}

The ability to treat ruptured and unruptured AVMs safely is a critical factor in determining management paradigms, especially since conservative approaches are actively debated in the literature..$^{36,38}$ The average annual hemorrhage risk has long been considered to be $2 \%-4 \%$, with the knowledge that AVM hemorrhage can be clinically devastating. An annual risk of death due to untreated AVMs has been estimated to be $1 \% .{ }^{27}$ Thirty-six percent of patients in the present study presented with a hemorrhage, and 15 patients (9\%) had a hemorrhage during the latency interval. This latency hemorrhage result equated to an annual hemorrhage risk rate of $2 \%$ and resulted in 9 deaths that were directly attributable to a hemorrhage.
Arteriovenous malformations within the optic radiation provide a challenge for clinical decision making because of the high risk of a new visual deficit that can impair quality of life, social functioning, and rehabilitation outcomes, especially if a homonymous hemianopia has occurred. ${ }^{5,32}$ Previous studies have indicated that a homonymous visual field deficit occurs in $67 \%-81 \%$ of patients with a previous hemorrhage and in 25\%-36\% of unruptured AVM cases in the occipital lobe. ${ }^{13,21}$ However, the natural history rate for visual field deficits in optic radiation AVMs is largely unavailable. In this study $36 \%$ of patients with a prior hemorrhage and $12 \%$ of those without had a visual field deficit at presentation, rates consistent with the results of Dehdashti et al. ${ }^{5}$ Microsurgical publications have documented rates of visual deficit from a prior hemorrhage as $26 \%-77 \%{ }^{18,24}$ If these data are extrapolated based on an annual AVM hemorrhage rate between $2 \%$ and $4 \%$, the risk of a visual deficit alone remains notable in the untreated population. Fortunately, from a treatment standpoint, Gamma Knife radiosurgery is associated with a relatively low risk profile. Less than $6 \%$ of patients developed a treatment-related visual field deficit, and only 1 patient developed a homonymous hemianopia after a single procedure in our study. ${ }^{23}$

Pollock et al. described a series of 34 patients treated at the University of Pittsburgh, which this study builds upon. ${ }^{31}$ Those authors identified 2 patients $(6 \%)$ who had developed a new visual field deficit. Compared with theirs, our data set has increased 5-fold to better evaluate risks and the correlation between AVM treatment and visual field preservation. Nonetheless, our results appear to correlate with the data published 17 years ago. We identified negative changes to visual fields in $9(5.6 \%)$ of 160 patients (11 patients excluded because of homonymous hemianopia at presentation). The actuarial rates of a visual deficit were $3 \%$ at 3 years, $5 \%$ at 5 years, and $8 \%$ at 10 years. The median interval until deficit detection was 25 months. Several factors appeared to be associated with the occurrence of a deficit. Women had an increased risk of a visual deficit, as did patients who developed reactive edema on follow-up imaging. Incomplete obliteration requiring a second SRS procedure also increased the risk of a new visual deficit. Moreover, there was a trend toward larger-volume AVMs resulting in an increased risk of a visual field deficit, but this trend did not reach statistical significance.

Several smaller SRS studies have demonstrated a wide distribution of new visual field deficits, with results ranging from $0 \%$ to $55 \% \%^{7,14,34}$ Maruyama et al. investigated the effect of radiation on the optic radiation through tractography based on diffusion tensor MRI in 10 simulated Gamma Knife treatments. ${ }^{22}$ Their data indicated that a maximum dose of $12 \mathrm{~Gy}$ or less to the optic radiation did not lead to new visual field deficits. This finding is not unexpected based on accepted brain tolerances of radiation, but it is below the standard margin dose required to effectively treat an AVM.

Surgical intervention and its effects on visual fields have been well documented in the literature on temporal and occipital AVMs. The reported rate of visual field deficits after the microsurgical management of AVMs in the occipital lobe ranges from $17 \%$ to $33 \% .^{1-3,5}$ Sinclair et al. reported on multimodal treatments for occipital lobe AVMs, 
with a surgical risk of $17 \%$ and a visual field deficit occurring in $21.7 \%$ of patients after combined embolization and surgery. ${ }^{34}$ Dehdashti et al. concluded that they would not recommend surgery unless the patient was aware of the risks, as the surgical arm of their study had a much higher rate of visual field deficits. ${ }^{5}$ These results are comparable to those of Lopez-Ojeda et al. in the temporal lobe, where the microsurgical management of AVMs resulted in a transient visual field deficit in $24 \%$ of patients and in long-term deficits in $16 \%$ of patients. ${ }^{18}$ This finding is supported by Boström et al., who showed a new significant postoperative visual field deficit in $19 \%$ of patients and worsening of preexisting visual field deficits in $43 \%$ of patients. ${ }^{4}$ Successful complete surgical removal provides the benefit of early hemorrhage protection but is associated with a higher risk of visual field deficits compared with SRS.

Research of stroke data has revealed a visual field loss rate of $40 \%$ with lesions in the occipital lobe, $30 \%$ with lesions in the parietal lobe, and $25 \%$ with lesions in the temporal lobe. ${ }^{27}$ However, the locations of all visual deficits in our study were relatively consistent across the lobes (30\% occipital, $32 \%$ parietal, and $27 \%$ temporal), which demonstrates the sensitivity of the white matter tracts of the optic radiation. ${ }^{7}$ Kupersmith et al. reported that spontaneous recovery occurred in $24 \%$ of visual field deficits after hemorrhage. ${ }^{13}$ We noted improvement in a similar number of patients who had presented with a visual field deficit.

Repeat SRS was undertaken when incomplete AVM obliteration was noted on MRI at 3 or more years after initial SRS to reduce the hemorrhage risk. ${ }^{29,39}$ Total obliteration was then confirmed in 18 of 30 patients. Furthermore, only one additional non-hemorrhage-related visual field deficit was identified in this group. Previous studies have reported permanent neurological deficits ranging from $2.8 \%$ to $3.6 \%$ in retreatment groups. ${ }^{11,42}$

\section{Study Limitations}

Limitations of this study largely relate to the duration of follow-up and the retrospective review of outcomes. In this subseries the average AVM volume was large, which often leads to the need for a second SRS. The timing and consistency of visual field testing (clinically performed in every patient) are also limitations, as not every patient underwent a formal visual field examination. Visual acuity was not assessed in this study since the major impact of postgeniculate optic pathways would be visual field loss rather than the visual acuity loss more commonly associated with anterior visual pathway dysfunction. Future studies can provide these additional data.

\section{Conclusions}

Postgeniculate visual pathway AVMs that were smaller than $5 \mathrm{~cm}^{3}$ in volume, that received $\geq 22$ Gy at the margin, or that had not been treated with prior embolization had the highest rates of total obliteration. New or worsened visual field deficits were identified in $5.6 \%$ of patients after a single SRS procedure. Female sex, the need for a second SRS procedure, and post-SRS edema were risk factors for a visual field deficit. In addition, we noted a trend toward a larger AVM volume as a risk factor. A homonymous hemi- anopia occurred in only one patient. This study indicates that Gamma Knife radiosurgery, compared with other modalities, was a relatively safe procedure and provided an effective means of treating a large percentage of the AVMs situated within the postgeniculate visual pathway.

\section{References}

1. Barrow DL, Dawson R: Surgical management of arteriovenous malformations in the region of the ventricular trigone. Neurosurgery 35:1046-1054, 1994

2. Bartolomei J, Wecht DA, Chaloupka J, Fayad P, Awad IA: Occipital lobe vascular malformations: prevalence of visual field deficits and prognosis after therapeutic intervention. Neurosurgery 43:415-423, 1998

3. Batjer H, Samson D: Surgical approaches to trigonal arteriovenous malformations. J Neurosurg 67:511-517, 1987

4. Boström A, Schaller K, Seifert J, Schramm J: The place for surgical treatment for AVM involving the temporal lobe. Acta Neurochir (Wien) 153:271-278, 2011

5. Dehdashti AR, Thines L, Willinsky RA, terBrugge KG, Schwartz ML, Tymianski M, et al: Multidisciplinary care of occipital arteriovenous malformations: effect on nonhemorrhagic headache, vision, and outcome in a series of 135 patients. Clinical article. J Neurosurg 113:742-748, 2010

6. Flickinger JC, Kondziolka D, Maitz AH, Lunsford LD: An analysis of the dose-response for arteriovenous malformation radiosurgery and other factors affecting obliteration. Radiother Oncol 63:347-354, 2002

7. Hayhurst C, Monsalves E, van Prooijen M, Cusimano M, Tsao M, Menard C, et al: Pretreatment predictors of adverse radiation effects after radiosurgery for arteriovenous malformation. Int J Radiat Oncol Biol Phys 82:803-808, 2012

8. Jones SA, Shinton RA: Improving outcome in stroke patients with visual problems. Age Ageing 35:560-565, 2006

9. Kano H, Kondziolka D, Flickinger JC, Park KJ, Iyer A, Yang $\mathrm{HC}$, et al: Stereotactic radiosurgery after embolization for arteriovenous malformations. Prog Neurol Surg 27:89-96, 2013

10. Kano H, Kondziolka D, Flickinger JC, Park KJ, Parry PV, Yang HC, et al: Stereotactic radiosurgery for arteriovenous malformations, Part 6: multistaged volumetric management of large arteriovenous malformations. J Neurosurg 116:5465,2012

11. Kano H, Kondziolka D, Flickinger JC, Yang HC, Flannery TJ, Awan NR, et al: Stereotactic radiosurgery for arteriovenous malformations, Part 3: outcome predictors and risks after repeat radiosurgery. J Neurosurg 116:21-32, 2012

12. Kano H, Kondziolka D, Flickinger JC, Yang HC, Flannery TJ, Niranjan A, et al: Stereotactic radiosurgery for arteriovenous malformations, Part 4: management of basal ganglia and thalamus arteriovenous malformations. J Neurosurg 116:33-43, 2012

13. Kupersmith MJ, Vargas ME, Yashar A, Madrid M, Nelson K, Seton A, et al: Occipital arteriovenous malformations: visual disturbances and presentation. Neurology 46:953-957, 1996

14. Kurita H, Ueki K, Shin M, Kawamoto S, Sasaki T, Tago M, et al: Headaches in patients with radiosurgically treated occipital arteriovenous malformations. J Neurosurg 93:224-228, 2000

15. Lawton MT, Lu DC, Young WL: Sylvian fissure arteriovenous malformations: an application of the Sugita classification to 28 surgical patients. Neurosurgery 61:29-38, 2007

16. Lindqvist M, Karlsson B, Guo WY, Kihlström L, Lippitz B, Yamamoto M: Angiographic long-term follow-up data for arteriovenous malformations previously proven to be obliterated after gamma knife radiosurgery. Neurosurgery 46:803-810, 2000

17. Liu L, Li H, Zheng J, Wang S, Zhao J, Cao Y: Sylvian fissure 
arteriovenous malformations: long-term prognosis and risk factors. Neurosurg Rev 36:541-549, 2013

18. Lopez-Ojeda P, Labib M, Burneo J, Lownie SP: Temporal lobe arteriovenous malformations: surgical outcomes with a focus on visual field defects and epilepsy. Neurosurgery 73:854-862, 2013

19. Lunsford LD, Kondziolka D, Flickinger JC, Bissonette DJ, Jungreis CA, Maitz AH, et al: Stereotactic radiosurgery for arteriovenous malformations of the brain. J Neurosurg 75:512-524, 1991

20. Lunsford LD, Niranjan A, Kano H, Kondziolka D: The technical evolution of gamma knife radiosurgery for arteriovenous malformations. Prog Neurol Surg 27:22-34, 2013

21. Martin NA, Wilson CB: Medial occipital arteriovenous malformations. Surgical treatment. J Neurosurg 56:798-802, 1982

22. Maruyama K, Kamada K, Shin M, Itoh D, Masutani Y, Ino $\mathrm{K}$, et al: Optic radiation tractography integrated into simulated treatment planning for Gamma Knife surgery. J Neurosurg 107:721-726, 2007

23. Monaco EA III, Niranjan A, Kano H, Flickinger JC, Kondziolka D, Lunsford LD: Management of adverse radiation effects after radiosurgery for arteriovenous malformations Prog Neurol Surg 27:107-118, 2013

24. Nagata S, Morioka T, Matsukado K, Natori Y, Sasaki T: Retrospective analysis of the surgically treated temporal lobe arteriovenous malformations with focus on the visual field defects and epilepsy. Surg Neurol 66:50-55, 2006

25. Nagy G, Major O, Rowe JG, Radatz, MW, Hodgson TJ, Coley $\mathrm{SC}$, et al: Stereotactic radiosurgery for arteriovenous malformations located in deep critical regions. Neurosurgery 70:1458-1471, 2012

26. Ondra SL, Troupp H, George ED, Schwab K: The natural history of symptomatic arteriovenous malformations of the brain: a 24-year follow-up assessment. J Neurosurg 73:387391, 1990

27. Pambakian AL, Kennard C: Can visual function be restored in patients with homonymous hemianopia? Br J Ophthalmol 81:324-328, 1997

28. Párraga RG, Ribas GC, Welling LC, Alves RV, de Oliveira E: Microsurgical anatomy of the optic radiation and related fibers in 3-dimensional images. Neurosurgery 71 (1 Suppl Operative):160-172, 2012

29. Pollock BE, Flickinger JC, Lunsford LD, Bissonette DJ, Kondziolka, et al: Hemorrhage risk after stereotactic radiosurgery of cerebral arteriovenous malformations. Neurosurgery 38:652-661, 1996

30. Pollock BE, Kondziolka D, Flickinger JC, Patel AK, Bissonette DJ, Lunsford LD: Magnetic resonance imaging: an accurate method to evaluate arteriovenous malformations after stereotactic radiosurgery. J Neurosurg 85:1044-1049, 1996

31. Pollock BE, Lunsford LD, Kondziolka D, Bissonette DJ, Flickinger JC: Stereotactic radiosurgery for postgeniculate visual pathway arteriovenous malformations. J Neurosurg 84:437-441, 1996

32. Rowe FJ, Wright D, Brand D, Jackson C, Harrison S, Maan $\mathrm{T}$, et al: A prospective profile of visual field loss following stroke: prevalence, type, rehabilitation, and outcome. Biomed Res Int 2013:719096, 2013

33. Shin M, Kawahara N, Maruyama K, Tago M, Ueki K, Kirino $\mathrm{T}$ : Risk of hemorrhage from an arteriovenous malformation confirmed to have been obliterated on angiography after stereotactic radiosurgery. J Neurosurg 102:842-846, 2005

34. Sinclair J, Marks MP, Levy RP, Adler JR, Chang SD, Lopez JR, et al: Visual field preservation after curative multi-modality treatment of occipital lobe arteriovenous malformations. Neurosurgery 57:655-667, 2005

35. Spetzler RF, Martin NA: A proposed grading system for arteriovenous malformations. J Neurosurg 65:476-483, 1986

36. Stapf C, Mohr JP: Unruptured brain arteriovenous malformations should be treated conservatively: yes. Stroke 38:33083309,2007

37. van Beijnum J, van der Worp HB, Buis DR, Al-Shahi Salman R, Kappelle LJ, Rinkel GJ, et al: Treatment of brain arteriovenous malformations: a systematic review and meta-analysis. JAMA 306:2011-2019, 2011

38. Wedderburn CJ, van Beijnum J, Bhattacharya JJ, Counsell CE, Papanastassiou V, Ritchie V, et al: Outcome after interventional or conservative management of unruptured brain arteriovenous malformations: a prospective, populationbased cohort study. Lancet Neurol 7:223-230, 2008

39. Yen CP, Jain S, Haq IU, Jagannathan J, Schlesinger D, Sheehan J, et al: Repeat Gamma knife surgery for incompletely obliterated cerebral arteriovenous malformations. Neurosurgery 67:55-64, 2010

40. Yen CP, Schlesinger D, Sheehan JP: Natural history of cerebral arteriovenous malformations and the risk of hemorrhage after radiosurgery. Prog Neurol Surg 27:5-21, 2013

41. Yen CP, Sheehan JP, Schwyzer L, Schlesinger D: Hemorrhage risk of cerebral arteriovenous malformations before and during the latency period after GAMMA knife radiosurgery. Stroke 42:1691-1696, 2011

42. Yen CP, Steiner L: Gamma knife surgery for brainstem arteriovenous malformations. World Neurosurg 76:87-98, 2011

43. Zipfel GJ, Bradshaw P, Bova FJ, Friedman WA: Do the morphological characteristics of arteriovenous malformations affect the results of radiosurgery? J Neurosurg 101:393-401, 2004

\section{Author Contributions}

Conception and design: Kano, Bowden, Lunsford. Acquisition of data: Kano, Bowden, Caparosa, Tonetti. Analysis and interpretation of data: Bowden. Drafting the article: Kano, Bowden, Lunsford. Critically revising the article: all authors. Reviewed submitted version of manuscript: all authors. Approved the final version of the manuscript on behalf of all authors: Kano. Study supervision: Kano.

\section{Correspondence}

Hideyuki Kano, Neurological Surgery, University of Pittsburgh, Ste. B-400, UPMC Presbyterian, 200 Lothrop St., Pittsburgh, PA 15213.email: kanoh@upmc.edu. 